Archived version from NCDOCKS Institutional Repository http://libres.uncg.edu/ir/asu/

Groothuis, P. A., \& Hill, J. R. (2013). Pay discrimination, exit discrimination or both? Another look at an old issue using NBA data. Journal Of Sports Economics, 14(2), 171-185. ISSN: 1527-0025. doi:

\title{
Pay Discrimination, Exit Discrimination or Both? Another Look at an Old Issue Using NBA Data
}

Peter A. Groothuis and James Richard Hill

\begin{abstract}
Economic literature has identified two potential types of racial discrimination in sports careers: exit discrimination and wage discrimination. The authors test for both types of discrimination in National Basketball Association (NBA) data in two ways. First using a modified Heckman procedure, they control for potential survival bias that may arise from exit discrimination in panel data and could possibly bias the coefficients of wage equations. Not controlling for survival bias could lead to false conclusions concerning the presence of pay discrimination. Using 1990-2008 NBA data, the authors fail to find any evidence of either pay or exit discrimination in the NBA utilizing this new technique. In one specification, however, a negative coefficient on the white dummy is found after controlling for height and being foreign-born suggesting that reverse discrimination is present. Yet, using a subset of the panel data used to examine pay discrimination in the NBA with career earnings the authors find that there is a pay premium paid to White players over their career in the magnitude of $16 \%-20 \%$, ceteris paribus. Neither of these results, however, is robust and highlights the pitfalls of using the residual method in measuring both pay and exit discrimination.
\end{abstract}

\section{Keywords}

NBA, Exit Discrimination, Pay Discrimination 


\section{Introduction}

Findings of discrimination in labor markets tend to garner much attention. This was particularly true when Kahn and Sherer (1988) proclaimed there was pay discrimination in the National Basketball Association (NBA) for Black players, despite a roughly similar prevailing average salary. The magnitude of the pay discrimination was said to be in the $20 \%$ range. This stirred quite a discussion in a sport where about $75 \%-80 \%$ of the players were Black. A summary of the findings even made it to the popular press. Proclamations of racial discrimination always elicit notoriety. Findings of no discrimination do not procure the same response. Therefore, it is important that any positive findings of racially unequal treatment be particularly robust.

In addition to findings of wage discrimination in the NBA, there have been findings of exit discrimination. Hoang and Rascher (1999) found evidence that White players were employed longer in the NBA than comparable Black players. This form of discrimination could be responsible for an even greater shortfall in pay for Black athletes than the more commonly researched wage discrimination.

From research on exit discrimination it is clear that individuals with greater ability have a higher survival rate. This leads to an overrepresentation of high ability workers at high levels of experience. This suggests that the coefficients of explanatory variables, including race, may be biased because in a panel data set the observations are not random.

In this article, we explore a modified-Heckman correction technique to correct for potential survival bias in wage equations using data from the 1990-2008 time period. This technique provides a logical extension of previous work on pay discrimination and exit discrimination by incorporating the results of exit discrimination into the wage equations directly. Further, we construct a subset of players whose entire careers began and ended within the 20-year period encompassed by our overall panel of data and test for discrimination in career earnings. In the next section, we provide a review of the previous literature on pay discrimination and exit discrimination in the NBA. Then we discuss how the inverse Mill's ratio can be used to correct for survival bias in wage equations. We then present the regression results for our wage equations using random effects panel estimates on salaries with one specification corrected using the inverse Mill's ratio and one using the standard model. In the remaining empirical section of the article, we explain the development of a new approach to examining discrimination using career earnings. Finally, we conclude with a discussion of the results concerning racial pay discrimination in the NBA and possible avenues for future research.

\section{Literature Review}

Following the article of Kahn and Sherer (1988) which used salary data from the 19851986 season, articles by Brown, Spiro, and Keenan (1991) and Koch and Vander Hill (1988) using 1984-1985 season salary estimated pay premiums for White players of $15 \%$ and $9 \%$, respectively, based on a standard residual methodology using dummy variables for race. All three studies cite fan discrimination as the driving force behind pay discrimination. 
Articles by Dey (1997), Gius and Johnson (1998), and Bodvarsson and Brastow (1999) using data from the late 1980s and 1990s failed to find racial wage discrimination. Hamilton (1997) found evidence of racial pay differences only at the upper end of the 1994-1995 season's salary distribution. Bodvarsson and Brastow (1999) suggested the disappearance of the pay discrimination in the NBA was the result of a decrease in owner monopsony power due to the negotiation of a new NBA Collective Bargaining Agreement in 1988 combined with the addition of four new teams. They also provide empirical evidence that at least part of the racial salary gap was the result of owner and manager discrimination, not just fan discrimination. Except for the article by Dey (1997), all the research in this area used single season salary data for model estimation. Dey used pooled data from five seasons in some of his empirical work.

Hill (2004) used an 11-year panel data set beginning with 1990 salaries and ending with 2000 salaries. While the coefficients for the dummy variable for White players were positive and significant in 1990 and 1991 individual year regression equations, the positive and significant finding in the overall pooled regression disappeared when height was added as an explanatory variable. Using data from the same year as Kahn and Sherer (1988), Hill also finds that the significance of race as a determinant of pay wanes when height is added to the model. Kahn and Shah (2005) claim, "For players who were neither free agents nor on rookie scale contracts, there were large statistically significant ceteris paribus nonwhite shortfalls in salary, total compensation, and contract duration." One weakness of their analysis, however, was that only 21 White players and 75 non-White players fell into this category of NBA player.

In addition to wage discrimination, exit discrimination has been addressed in the sports economic literature. Hoang and Rascher (1999) define exit discrimination as "the involuntary dismissal of workers based on the preferences of employers, coworkers, or customers." They concluded that career length for Black players in the NBA were lower than their White counterparts, ceteris paribus. Hoang and Rascher calculate that this form of discrimination led to almost a $2 \frac{1}{2} 2$ times greater decrease in Black career pay compared to the more heavily analyzed form of pay discrimination. Groothuis and Hill (2004) also focusing on career duration but on a later time period than Hoang and Racher (1999) found that performance and weight of the basketball player determined career length. They, however, found that the race of the player did not matter. The results of both the wage and exit discrimination literature suggest that both exit and wage discrimination existed in the NBA but have diminished with time.

\section{Data Description}

The data set used in this study consists of yearly performance statistics for NBA players between 1990 and 2008, salary figures between 1990 and 2008, and 
Table 1. Means.

\begin{tabular}{|c|c|c|c|}
\hline Variable & Means & Means White & Means Black \\
\hline Salary & $\begin{array}{l}\$ 2,920,100 \\
(3,470,474) \\
\text { Max } \$ 33,100,000 \\
\text { Min } \$ 120,000\end{array}$ & $\begin{array}{l}\$ 2,497,834 \\
\quad(2,685,170) \\
\text { Max } \$ 15,694,250 \\
\text { Min } \$ 120,000\end{array}$ & $\begin{array}{l}\$ 3,035,009 \\
(3,646,859) \\
\text { Max } \$ 33,100,000 \\
\text { Min } \$ 120,000\end{array}$ \\
\hline Career length & $\begin{array}{l}6.95 \text { (seasons) (5.02) } \\
\text { Min I } \\
\text { Max } 20\end{array}$ & $\begin{array}{l}6.29 \text { (seasons) (4.68) } \\
\text { Min I } \\
\text { Max } 19\end{array}$ & $\begin{array}{l}7.24 \text { (seasons) (5.12) } \\
\text { Min I } \\
\text { Max } 20\end{array}$ \\
\hline Height & 79.2 (inches) (3.75) & 80.8 (inches) (3.85) & 78.7 (inches) (3.60) \\
\hline $\begin{array}{l}\text { Body mass index } \\
\text { Points per season }\end{array}$ & $\begin{array}{l}24.7(1.88) \\
569(487)\end{array}$ & $\begin{array}{l}24.7(1.49) \\
462(415)\end{array}$ & $\begin{array}{l}24.7(1.97) \\
604(501)\end{array}$ \\
\hline $\begin{array}{l}\text { Rebounds per } \\
\text { season }\end{array}$ & $245(209)$ & $210(185)$ & $252(213)$ \\
\hline Blocks per season & $117(405)$ & $117(4 \mid 4)$ & $117(403)$ \\
\hline Assists per season & $169(214)$ & $14 \mid(207)$ & $170(215)$ \\
\hline Draft number & $36.2(25)^{\prime}$ & $38.3(24)$ & $35.5(25)$ \\
\hline Foreign born & $0.07(.25)$ & $0.24(.44)$ & $0.02(.12)$ \\
\hline $\begin{array}{l}\text { Number } \\
\text { observations }\end{array}$ & 6,512 & 1,393 & 5,119 \\
\hline White & $\begin{array}{l}21.45 \% \text { of } \\
\text { observations }\end{array}$ & - & - \\
\hline
\end{tabular}

biographical data, which consists of height, weight, birth date, and a dummy variable equal to zero for African American players and one otherwise, and a dummy variable for foreign-born players.1 Body mass index (BMI) was also calculated for each player; BMI equals weight, in pounds, times 703 divided by height, measured in inches, squared. Each player's draft number ranging from 1 for the first player selected to 60 for the last player selected.

Table 1 provides descriptive statistics for our overall data set and for the subset of White and Black players, respectively. The salary figures indicate that Black players enjoyed a substantially higher salary on average than White players. Keep in mind that these figures are in nominal terms over a 19-year span. Average career length for our sample is 6.95 seasons with Black players averaging almost a full season longer career span than White players: 7.24 versus 6.29. White players in our study are over two inches taller on average than their Black counterparts, 80.8 inches compared to 78.7 inches. However, the BMI is the same for all players. Black players outperform White players by a wide margin on three of the four performance statistics used in our study: points per season, rebounds per season, and assists per season; only blocks per season are equal between the groups. The draft number is lower on average for Black players by about three spots in the draft, 35.5 versus 38.3; Black players are selected earlier on average on draft day. A little over $21 \%$ of our sample consists of White players; $7 \%$ of the sample is foreign-born.

\section{Duration Effects and Sample Selection Bias}

In an attempt to combine both the wage and exit discrimination literature, we use a modified Heckman procedure to control for both exit discrimination and survival bias in 
panel study wage equations. The Heckman (1979) procedure has long been used by economists to control for self-selection in a sample. In our case, we suggest that both performance and race may change the likelihood of survival in the NBA. We explore if a modified Heckman procedure controls for survival bias in wage equations. Following Greene's (1997) notation, consider the basic sample selection model where,

$$
d_{i} *=z^{\prime} \gamma+v \text { and } d_{i}=1 \text { if } d_{i} *>0 ; d_{i}=0 \text { otherwise }
$$

$$
y_{i}=x^{\prime} \beta+\varepsilon_{i}+v_{j} \text { where } i \text { is for each observation and } j \text { for each player. }
$$

and $y$ is only observed if di is equal to 1 . Suppose as well that $u$ and e have a bivariate normal distribution with zero means and a correlation of $r$. Then

$$
E(y \mid y \text { is observed })=E\left(y \mid d^{*}>0\right),
$$$$
=E\left(y \mid v>-z^{\prime} \gamma\right) \text {, }
$$$$
=x^{\prime} \beta+E\left(\epsilon \mid v>-z^{\prime} \gamma\right),
$$

$$
=x^{\prime} \beta+\rho \sigma_{\epsilon} \lambda\left(\alpha_{v}\right),
$$

Where I(au) is the inverse Mill's ratio. The overall equation of interest becomes

$$
y_{i}\left|d^{*}>0\right|=x^{\prime} \beta+\rho \sigma_{\epsilon} \lambda\left(\alpha_{v}\right)+\epsilon_{i},
$$

Thus the marginal effect of a regressor in the observed sample consists of two parts

$$
\frac{\partial E(y \mid y \text { is observed })}{\partial x_{k}}=\beta_{k}+\gamma_{k}\left(\rho \sigma_{\epsilon} / \sigma_{v}\right) \lambda\left(\alpha_{v}\right),
$$

where the first part $b$ is the marginal effect of the observed equation and $g$ is the influence the variable has on the likelihood of being observed. Heckman (1979) recommends a two-step procedure: first, estimate a probit on the selection equation to obtain estimates of $\mathrm{g}$. Then estimate the random effects panel regression along with the inverse Mill's ratio to estimate b and bl. Verbeek and Nijman (1992) show that for a random effects panel Heckman's (1979) lambda (I) is appropriate as long as there is no individual effects in the probit selection equation. This is the case in our selection equation of career duration.

In our case, the selection equation comes from Equation 1 from the above career duration model. To calculate the inverse Mill's ratio, we estimate semi-parametric hazard functions following Berger and Black (1988), Berger, Black, and Scott (2004), 
and Groothuis and Hill (2004); since our data is at the season level we calculate our hazard model as a discrete random variable. As with Berger et al., we model the durations of a single spell and assume a homogeneous environment so that the length of the spell is uncorrelated with the calendar time in which the spell begins. This assumption lets us treat all the players' tenure as the same, regardless of when it occurred in the panel study. For instance, all fourth-year players are considered to have the same baseline hazard, regardless of calendar time so a fourth-year player in 1990 has the same baseline hazard as a fourth-year player in 1997.

As the hazard function is the conditional probability of exiting NBA, given that the NBA career lasted until the previous season, the hazard function must have a range from 0 to 1. In principle, any mapping with a range from 0 to 1 will work. For our purposes we choose the probit model. We choose the probit model over the more traditional logit model in hazard models because the probit model provides the benefit of the ability to calculate the inverse Mill's ratio.

The intuition behind the probit model for the hazard function is relatively simple. For each year during the survey in which the player is in NBA, the player either comes back for another season or ends his career. If the career ends, the dependent variable takes on a value of 1 ; otherwise, the dependent variable is 0 . The player remains in the panel until the player exits NBA or the panel ends. If the panel ends, we say the worker's spell is right-hand censored. Thus a player who begins his NBA career during the panel and plays for 6 years will enter the data set 6 times: the value of his dependent variable will be 0 for the first 5 years (tenure 1 through 5) and be equal to 1 for the sixth year.

To illustrate a stock sample, consider another player who enters the panel with 7 years of NBA job tenure prior to 1989 the first year of the panel, then plays for an additional 3 years for a 10-year career. For this player, we ignore his first 7 years of tenure because he is left-hand censored. As the equation of the likelihood function with stock data indicates, the duration of a NBA career prior to the beginning of the panel makes no contribution to the value of the likelihood function. Therefore, only years 8through 10 will enter the data set with the dependent variable taking on the value 0 for years 8 and 9 and in the 10th year it takes on a value of 1 with this player appearing in the data set a total of 3 times. Note for all players who are right-hand censored, we do not know when their career ends so their dependent variables are always coded as 0 .

Because the players in the panel have varying degrees of job tenure prior to the beginning of the panel, we identify the hazard function for both long and short careers. The disadvantage to this approach is that the vector of dummy variables to control for each year of tenure can be very large. In our study, it would require 20 dummy variables, one for each year of the longest career. In addition, we run into problems with the dummy variable technique because we have too few players who have long careers. To simplify the computation of the likelihood function and be able to keep the long careers, we simply approximate the gt vector with a fourth- order polynomial of the players' tenure in NBA, which reduces the number of parameters to be estimated from 21 to 4 . Thus, the hazard function becomes 


$$
\operatorname{Pr}(t, x \beta)=\operatorname{Pr}(\phi(t)+x \beta),
$$

where $f(t)$ is a fourth-order polynomial of the player's tenure in NBA. The fourth-order polynomial therefore includes tenure to the first, second, third, and fourth powers. Once again, we choose the Taylor series approximation technique over using tenure dummies due to the small number of observations for high tenures. The probit estimates the probability of exiting from a career, so instead of estimating the probability of being in the sample, as in Heckman's approach, we estimate the probability of exiting the sample.

\section{Duration Results}

In Table 2, we report the results of the career duration semi-parametric analysis. We find that increases in all performance measures increase career length, while increases in draft number has a concave relation with career duration with increases in draft number increasing the probability of exit but at a decreasing rate. Both of these results suggest that performance increases the length of players' careers suggesting that panel data may suffer from survival bias. In addition, we find increases in a player's BMI raise the probability of exiting. The BMI was included to control for health issues that might influence career length. When it comes to exit discrimination, the coefficient on race is insignificant as is the coefficient on foreign-born. Overall, the results suggest the career length depends upon performance and not race or ethnicity. To control for survival bias, we calculate the inverse Mill's ratio from this equation.

\section{Wage Equations Results}

In Table 3, we report the results of six log wage equations for NBA players using both fixed and random effects panel models. Verbeek and Nijman (1992) and Vella (1998) show that selectivity bias exists in panels and can be addressed with Heckman procedures. The wage equations cover the 1991-2008 seasons with the performance variables lagged in the wage equations. Independent variables include the same list used for the probit model of Table 2 with the exception of BMI and the higher order tenure variables. Following the findings of Hill (2004), height is included in the wage equation to make sure the race variable does not serve as a proxy for height of a player in specifications III and V. Height is excluded in the random effects specifications I, II, and IV to provide comparisons for the race variable when height is included. The dummy of foreign-born is excluded in I, II, and III to explore the robustness of the results of the race dummy variable. Tenure and tenure squared are inserted as explanatory variable to capture the traditional shape of the age earnings profile. Dummy variables are inserted for each year except 2008 to control for inflationary factors in pooling yearly data. The inverse Mill's ratio 
Table 2. NBA Career Duration Semiparametric Analysis: 1989-2008.

\begin{tabular}{lr} 
Variable & Probit Model \\
\hline Constant & $-2.02(5.40)$ \\
White & $-0.023(0.38)$ \\
Foreign born & $0.145(1.40)$ \\
Body mass index & $0.023 *(1.69)$ \\
Points per season & $-0.0004(3.48)$ \\
Rebounds per season & $-0.0025(8.14)$ \\
Blocks per season & $-0.0014(1.54)$ \\
Assists per season & $-0.0006(2.60)$ \\
Draft number & $0.013(5.38)$ \\
Draft number squared & $-0.649(2.94)$ \\
Chi-square & 741.84 \\
Number of observations & 6,530
\end{tabular}

is included in all specifications except the first as an additional independent variable to correct for both exit discrimination and survival bias. The results of the log wage regressions in Table 3 all follow most of the traditional patterns.

First, the expected results: in all four models, the coefficients of tenure are positive and significant; the coefficients of tenure squared are negative and significant. The shape of the age/earnings profile follows the classic pattern found throughout labor markets in general. Wages are also negatively and significantly correlated with draft number in a concave manner; earlier picks in the draft earn more money but the affect is less pronounced lower in the draft. Player performance measures are all statistically significant. Height itself is found to have a positive and significant effect on pay in all specifications. The dummy variables for each year follow the expected pattern: each year has a negative and significant effect on wages; only the coefficient of the dummy variable for 2007 is not significant. These results are excluded from the table and are available from the authors by request.

The lack of significance of the dummy variable for White players in all the random effects specification except for specification $V$ is also not surprising, given that most current research has not found discrimination in the NBA. The negative coefficient found in specification $\mathrm{V}$, although surprising, highlights the problem of the residual technique in measuring labor market discrimination. Once controlling for NBA players who are foreign-born, where the vast majority are white, and for height, where White players are two inches taller than Black players, reverse discrimination is potentially found. The question then becomes are there other variables that are excluded where race serves as a proxy for missing variables. Model VI provides a fixed-effect comparison to the random effects models. The Hausman test suggests that the fixed-effect model is the statistically appropriate model. The fixed-effects model is appropriate because there is some correlation between the 
Table 3. Log Wage Regressions: 1990-2008.

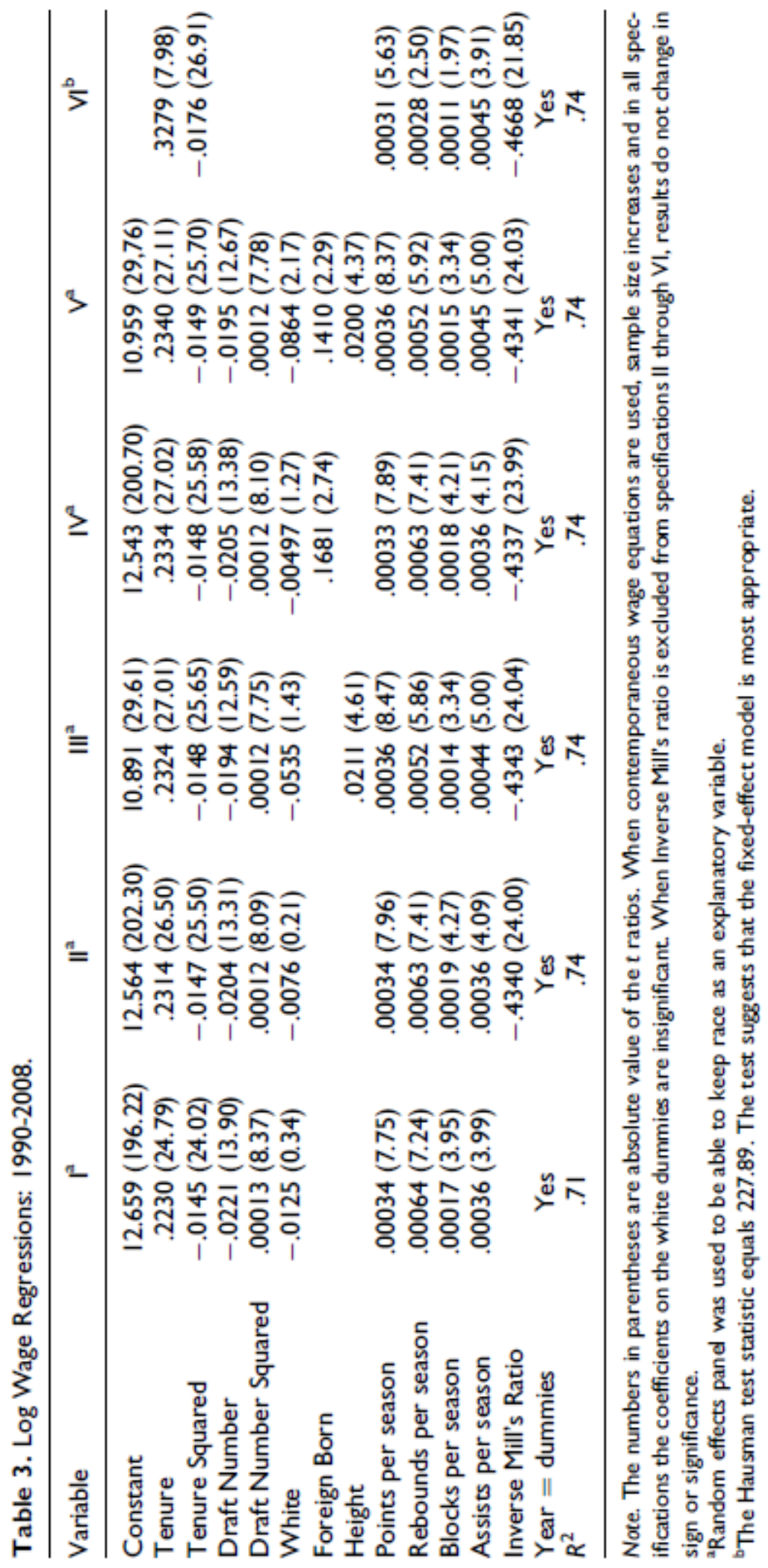


Xs and the error term making the random effects estimates inconsistent. Therefore, using the random effects model is inappropriate and the coefficients on race must be viewed with caution.

The coefficient of the inverse Mill's Ratio is found to be negative and significant in all models. Survival bias appears to exist in the determination of wages but surprisingly the correction for survival bias does not significantly change the coefficients of any variables in the model. Perhaps the inverse Mill's Ratio is capturing some heretofore unmeasured player trait that affects duration and salary but is unrelated to performance. Such traits could include personality, character, and/or leadership ability; all of these are difficult to quantify but desirable qualities for which management may pay a premium. While the construction of the modified Heckman technique may provide a new theoretical approach to capturing previously unquantifiable worker characteristics, it does not appear to offer any new insight into the measurement of racial pay discrimination. However, given the length of our panel data, an alternative approach exists that encompasses the lingering effects of any exit and/or wage discrimination from a different perspective.

\section{Career Earnings Regression Analysis}

Restricting our panel to players who began their careers in 1990 or later and ended their careers before the 2008 season, we create a deflated summation of these players' career earnings. 6 Summary statistics for the 707 players in this sample are shown in Table 4. African Americans born in the Unites States account for $70.4 \%$ of the sample while White players born in the United States total $18.1 \%$ of the group. Black and nonBlack foreign-born players compose just $2.3 \%$ and $9.2 \%$ of the sample, respectively. The Black U.S. players have higher career earnings on average than any of the other groups listed. They also have higher performance statistics on average for five of the six measures listed. The average height of the U.S.-born Black players is lower by over two inches or more compared to the other groups.

We regress the log of the players' deflated career earnings on a vector of demographic and performance variables: draft number and draft number squared, dummy variables equal to 1 for White and foreign-born players, height, BMI, average career points per game, average career rebounds per game, average career assists per game, average career steals per game, average career blocks per game, and average career turnovers per game. The results of four different versions of the basic model are presented in Table 5. In Model I, all of the variables listed above are included in the regression equation. All of the performance variables are properly signed and significant at the $10 \%$ level or better. Career earnings rise with average career points, rebounds, assists, steals, and blocks; career earnings fall as average career turnovers increase. Players drafted earlier receive significantly higher lifetime earnings; the coefficient of draft number squared is insignificant. The coefficient of height is also not found to be significant. The variable body mass index does not display any 
Table 4. Summary Statistics for Career Earnings Regressions Data: 1990-2007.

\begin{tabular}{lllll} 
& Black & White & Black & White \\
Mean Value, SD, Observations & U.S.-Born & U.S.-Born & Foreign-Born & Foreign-Born \\
\hline Career earnings & $\$ 6,838,607$ & $\$ 5,114,891$ & $\$ 5,702,803$ & $\$ 2,812,104$ \\
Maximum & $1.22 \mathrm{e}+07$ & 8985476 & 297047.8 & 5293824 \\
Minimum & 498 & 128 & 16 & 65 \\
Draft number & 38.4498 & 37.85938 & 49.5625 & 42.29231 \\
& 21.4441 & 20.65568 & 14.36184 & 19.03674 \\
Height & 498 & 128 & 16 & 65 \\
& 78.37149 & 80.73438 & 81 & 81.66154 \\
Average career points & 3.408557 & 3.929465 & 3.63318 & 3.813123 \\
& 498 & 128 & 16 & 65 \\
Average career rebounds & 5.600747 & 4.070464 & 2.824209 & 3.971501 \\
& 3.851078 & 2.652568 & 1.327662 & 2.966858 \\
Average career assists & 498 & 128 & 16 & 65 \\
& 2.495278 & 2.321935 & 1.538312 & 2.058039 \\
& 1.73494 & 1.545347 & .7742251 & 1.330368 \\
Average career steals & 498 & 128 & 16 & 65 \\
& 1.270905 & .8606273 & .4220985 & .7185972 \\
& 1.208284 & .8654169 & .4452761 & .7908073 \\
Average career blocks & 498 & 128 & 16 & 65 \\
& .5199734 & .3353073 & .217481 & .3103613 \\
Average career turnovers & .3466287 & .2363093 & .1801428 & .2565885 \\
& 498 & 128 & 16 & 65 \\
& .2815093 & .2843318 & .2220538 & .236982 \\
& .3257839 & .3610661 & .1572721 & .2745816 \\
& 498 & 128 & 16 & 65 \\
& 1.008087 & .7010346 & .5038951 & .7330243 \\
& .9119674 & .4463059 & .222593 & .4418539 \\
& 498 & 128 & 16 & 65 \\
& & & &
\end{tabular}

explanatory power. The coefficient of foreign-born is insignificant as well. However, the coefficient of the dummy variable for White is positive and significant at the $10 \%$ level. In regression Model II, BMI is dropped from the regression. None of the results from Model I are changed. In Model III, both body mass index and foreign-born are dropped from the basic regression equation. All the coefficients of the remaining variables are essentially unchanged; the t statistics of all the coefficients are also essentially unchanged except for a slight increase in the level of significance for White. To see if there is a correlation between Height and White as was found by both Groothuis and Hill (2004) in their duration analysis research and Hill (2004) in his panel and pooled ordinary least squares (OLS) wage regression results, we remove Height from the equation for Model IV. The coefficient of White rose by over $25 \%$ and the level of significance increased. In Model $\mathrm{V}$, only variables that are fixed at the time the player enters the NBA are included: draft number, draft number 
Table 5. Career Earnings Regressions: 1990-2007.

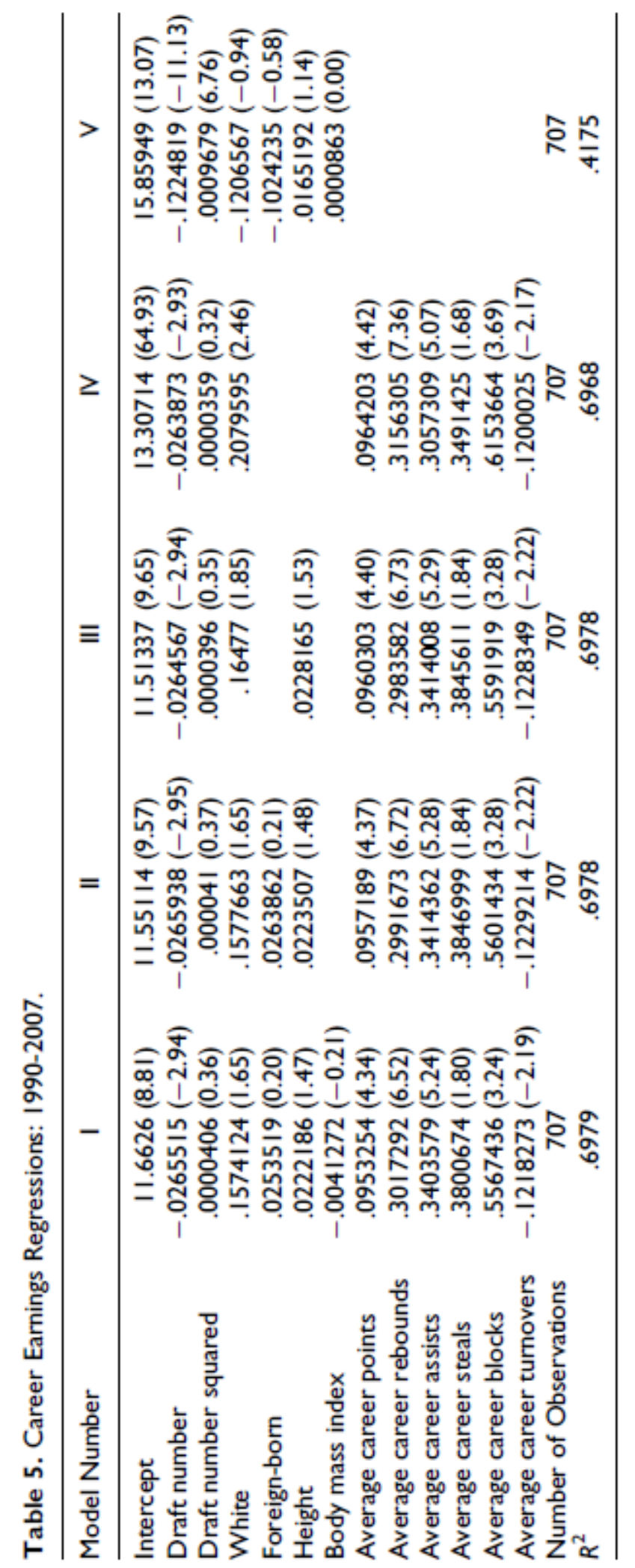


squared, dummy variable for White players, dummy variable for foreign-born players, height, and body mass index. This provides an "ex ante" view of the impact of being White on career earnings. The coefficient of White is not significant in this model nor are the coefficients of height, body mass index, and foreign-born.

In all the models except Model $\mathrm{V}$, the coefficient of the dummy variable for White is positive and significant suggesting a career pay premium for White players over and above levels suggested by their performance or draft position. The size of the premium varies from $15.7 \%$ to $20.8 \%$ depending on whether height is included in the model. However, the results of Model V suggest that these results are due to the endogeneity between career averages performance statistics and race.

Conclusions, Implications, and Suggestions for Future Research

The introduction of a Heckman Bias Technique modified for survival rather than selectivity fails to uncover any residual exit or pay discrimination in the NBA during the 1990s through the 2008 except in one specification where reverse discrimination is found. This result, however, is not robust and is inconsistent because the fixed-effect model is found to be the superior technique. We suggest that caution should be used when interpreting the coefficients on the dummy variable on race in the residual technique. In addition, the new approach found that survival bias is present in NBA data but coefficients of wage equation variables are unaffected. These results suggest that on one hand researchers using panel data may feel satisfied that the lack of biased coefficients in our wage equations might mean such a bias does not exist. Caution should be exercised in this judgment. Sports wages are extremely deterministic compared to other market structures in which good performance variables are lacking. The technique introduced here to correct for survival bias needs to be tried in other labor market settings. This could prove a fruitful area for future research.

The most surprising result of our analysis is found when we focus our attention on discrimination in career earnings. We find a premium paid in career earnings to White players, ceteris paribus, in the magnitude of $16 \%-21 \%$. Using the same data provides conflicting results; in the panel study, reverse discrimination is found; in career earnings, discrimination is found. We suggest the conflicting results are due to the limitations of the dummy variable technique. The results are not robust. Research that uses the residual method to measure discrimination must be viewed with a great deal of caution.

\section{Declaration of Conflicting Interests}

The authors declared no potential conflicts of interest with respect to the research, authorship, and/or publication of this article

\section{Funding}

The authors received no financial support for the research, authorship, and/or publication of this article. 


\section{Notes}

1. Salary figures, height, weight, and draft numbers were obtained from Patricia Bender's website: http://www.eskimo.com/*pbender/index.html. Performance statistics were found at Dougs' NBA and MLB Statistics website: http://www.dougstats.com/. Data on race and place of birth were extracted from a variety of internet sources.

2. In some years, there were less than 30 teams in the league. For undrafted players or for players who were selected when there were more than two rounds in the draft prior to 1989 , we assigned 65 as the player's draft number.

3. To see theoretical underpinnings of the duration model used in this article, see Groothuis and Hill (2004, 2008).

4. When higher order polynomials of the fifth and sixth power are included, results do not change suggesting that a fourth-order polynomial is flexible enough to capture the influence of the baseline hazard.

5. We are indebted to an anonymous referee of the Journal of Sports Economics for suggesting this approach.

6. We deflated salaries using a 1982-1984 base year CPI index. 


\section{References}

Berger, M. C., \& Black, D. A. (1988). The duration of Medicaid spells: An analysis using flow and stock samples. The Review of Economics and Statistics, 80, 667-674.

Berger, M. C., Black, D. A., \& Scott, F. (2004). Is there job lock? Evidence from the pre-HIPAA era. Southern Economic Journal, 70, 953-976.

Bodvarsson, O. B., \& Brastow, R. T. (1999). A test of employer discrimination in the NBA. Contemporary Economic Policy, 17, 243-255.

Brown, E., Spiro, R., \& Keenan, D. (1991). Wage and non-wage discrimination in professional basketball: Do fans affect it? American Journal of Economics and Sociology, 50, 333-345.

Dey, M. S. (1997). Racial differences in national basketball association players' salaries: A new look. American Economist, 41, 84-90.

Gius, M., \& Johnson, D. (1998). An empirical investigation of wage discrimination in professional basketball. Applied Economics Letters, 5, 703-705.

Greene, W. H. (1997). Econometric analysis (3rd ed.). Upper Saddle River, NJ: Prentice Hall.

Groothuis, P. A., \& Hill, J. R. (2004). Exit discrimination in the NBA: A duration analysis of career length. Economic Inquiry, 42, 341-349.

Groothuis, P. A., \& Hill, J. R. (2008). Exit discrimination in Major League Baseball: 1990-2004. Southern Economic Journal, 75, 574-590.

Hamilton, B. H. (1997). Racial discrimination and professional basketball salaries in the 1990's. Applied Economics, 29, 287-296.

Heckman, J. (1979). Sample selection bias as a specification error. Econometrica, 47, 153-161.

Hill, J. R. (2004). Pay discrimination in the NBA revisited. Quarterly Journal of Business and Economics, 43, 81-92.

Hoang, H., \& Rascher, D. (1999). The NBA, exit discrimination, and career earnings. Industrial Relations, $38,69-91$.

Kahn, L. M., \& Shah, M. (2005). Race compensation and contract length in the NBA: 2001-2002. Industrial Relations, 44, 444-457.

Kahn, L. M., \& Sherer, P. D. (1988). Racial differences in professional basketball players compensation. Journal of Labor Economics, 6, 40-61.

Koch, J. V., \& Vander Hill, C. W. (1988). Is there discrimination in the 'Black Man's Game’? Social Science Quarterly, 69, 83-94. 
Verbeek, M., \& Nijman, T. (1992). Testing for selectivity bias in panel data models. International Economic Review, 33, 681-703.

Vella, F. (1998). Estimating models with sample selection bias: A survey. The Journal of Human Resources, 33, 127-169. 